\title{
Exploring user gains in Participatory Design Processes with vulnerable children
}

\author{
Selina Schepers \\ Social Spaces, LUCA School of Arts, \\ KU Leuven \\ C-mine 5, Genk, Belgium \\ Selina.schepers@luca-arts.be
}

\author{
Katrien Dreessen \\ Social Spaces, LUCA School of Arts, \\ KU Leuven \\ C-mine 5, Genk, Belgium \\ Katrien.dreessen@luca-arts.be
}

\author{
Bieke Zaman \\ Meaningful Interactions Lab (Mintlab), \\ KU Leuven - imec \\ Parkstraat 45, Leuven, Belgium \\ Bieke.zaman@kuleuven.be
}

\begin{abstract}
This paper contributes to the debate on benefits that children can gain through their involvement in Participatory Design (PD) and highlights the importance of user gains in relation to vulnerable children. As vulnerable children are prone to marginalisation, this paper explores the user gains they may acquire when participating in $\mathrm{PD}$ processes. We report on the results of 'Making Things!': a long-term PD project to (co)design FabLab workshops for the future together with local, vulnerable children (6-12 y/o). The analysis points to three benefits that these children gain through their participation: developing self-esteem, learning-by-doing, and broadening their horizons. Based on our findings, we pinpoint the importance of an approach to PD that is sensitive to the complexities of participants (cf. 'Design for vulnerability') and discuss the need for suitable methods to assess children's user gains. ${ }^{1}$
\end{abstract}

\section{CCS CONCEPTS}

- Human-centered computing $\rightarrow$ Participatory design

\section{KEYWORDS}

Participatory Design, user gains, child participants, vulnerability.

\section{ACM Reference format:}

S. Schepers, K. Dreessen, and B. Zaman. 2018. Exploring user gains in Participatory Design Processes with vulnerable children. In $P D C$ '18: Proceedings of the 15th Participatory Design Conference - Volume 1, August 20-24, 2018, Hasselt and Genk, Belgium, 5 pages.

https://doi.org/10.1145/3210604.3210617

Permission to make digital or hard copies of all or part of this work for personal or classroom use is granted without fee provided that copies are not made or distributed for profit or commercial advantage and that copies bear this notice and the full citation on the first page. Copyrights for components of this work owned by others than the author(s) must be honored. Abstracting with credit is permitted. To copy otherwise, or republish, to post on servers or to redistribute to lists, requires prior specific permission and/or a fee. Request permissions from Permissions@acm.org.

PDC '18, August 20-24, 2018, Hasselt and Genk, Belgium

(C) 2018 Copyright is held by the owner/author(s). Publication rights licensed to ACM.ACM ISBN 978-1-4503-5574-/18/08...\$15.00

https://doi.org/10.1145/3210604.3210617

\section{INTRODUCTION}

Participants are at the heart of PD; previous studies [1, 2, 3] have suggested that they can and should benefit through PD. While several PD researchers have explored 'user gains', benefits that children can gain from PD remain relatively unexplored [4]. In this paper, we start from the premise that a central focus on what children gain from their involvement in PD can lead to genuine children's participation, fitting the democratising values of the early Scandinavian PD tradition [5]. Research on children in PD processes is often criticised for being "reduced PD" [6, p. 27]. In contrast, genuine children's participation should enable their voices to be heard and empower them [7].

We explore user gains in PD processes involving children, and more specifically vulnerable children ${ }^{2}$. Children's competence and ability to contribute to a PD process are regularly underestimated; particularly vulnerable children - e.g. in developing countries [8] - are prone to marginalisation or ignored [9]. We report on the results of 'Making Things!': a long-term PD project to (co-)design FabLab workshops for the future together with local, vulnerable children (6-12 y/o). In doing so, this paper contributes to the debate on benefits children can gain through PD processes and highlights the importance of user gains in relation to vulnerable children.

\section{CHILDREN'S USER GAINS}

There is a dearth of literature on the benefits children can gain from PD. Previous research on adult user gains (e.g. [1, 2, 3]) has already shed some light on what user gains in PD processes might entail. For instance, Bossen et al [1] have determined that users can gain at a personal level (e.g. gaining new career opportunities) and at a collective level (e.g. increasing their competence in working in interdisciplinary groups). Research on user gains for child-participants in $\mathrm{PD}$ processes is scarcer. Benton et al [10], Hussain [9], Yang [11] and McNally et al [12] include four of the few contributions to the literature. When involving children with Autism Spectrum Disorders (ASD) in $\mathrm{PD}$, Benton et al [9] have reported on gains such as gaining

\footnotetext{
${ }^{2}$ In previous research (e.g. [13, 14]), vulnerable users are described as people at risk because of their socioeconomic status, diagnosis or limited capacities. Therefore, we use the term 'vulnerable' children.
} 
confidence to voice opinions. Hussain [10] on her part has suggested that empowerment is important consider, while Yang [11] has concluded that former street children in the Philippines generally felt more independent and creative as a result of participation. McNally et al [12] have investigated gains former child participants perceive from their participation, including design process knowledge. Literature on children's user gains points to a need for further explicating the benefits children gain from their involvement in PD. This paper contributes to this topic by reporting on gains we distinguished in a PD with vulnerable children.

\section{CASE STUDY: 'MAKING THINGS!'}

'Making Things!' is a PD project (2015 - August 2018), set up by two design researchers of FabLab Genk (part of LUCA School of Arts) together with local youth work organisation 'LYWO'3. LYWO offers activities in leisure time - ranging from playing outside, doing arts and crafts to swimming lessons - with attention to the wellbeing of vulnerable children. 'Making Things!' aims for designing FabLab workshops for the future, in a participatory manner (for children participating in FabLabs or making activities, see e.g. [15] and [16]). By encouraging the children to design the workshops themselves before effectively participating in them, we hope they can create appealing FabLab workshops, which can also be used after completion of 'Making Things!' or appropriated by other stakeholders. In this way, the case study is an exploration of providing children with opportunities to (co-)design PD processes and is grounded in Schepers, Dreessen \& Zaman's research on 'the child as process designer' [17]. We hypothesize that allowing children to (co)define a PD process and its methods results in more opportunities to experience user gains.

\subsection{Participants}

In 'Making Things!', between 55 and 65 local children (6-12 y/o), eight youth workers and two design researchers were involved. The participating children all came from Genk-Zuid: a specific district in the city of Genk (Belgium), characterized by its spatial isolation, deprivation and a weak socio-economic profile of the residents (high unemployment, etc.). It is a social housing estate, distinguished by large apartment buildings, with its population being mainly from Turkish and Moroccan descent. As participation in LYWO's activities was voluntary, the group of children changed every week; a core group of about 25 - 35 of the same children participated in the PD activities. Children and their parents were informed and had the opportunity to ask questions or refrain from taking part, before the start of the project. In doing so, we attempted to make the PD project transparent for the child-participants and their parents [18].

\subsection{Process}

${ }^{3}$ Pseudonyms are used to ensure the privacy of the participants and organisation.
Inspired by existing PD methods for children (e.g. Druin's Cooperative Inquiry [19]), we engaged with the participants in an iterative methodological process entailing (1) participatory observations and sensitising packages; (2) a first iteration of the workshops; (3) evaluations; and (4) a second iteration of the workshops, followed by evaluative interviews.

First, six sessions of participant observations [20] - of more than 60 boys and girls - were carried out in the period between April and May 2016, to gain insights in children's life worlds and generate ideas for the design of the workshops. Afterwards, 20 children also received a sensitising package: two assignments in which the children - through drawing and crafting - expressed their ideas on the workshops [21].

In the second project phase, 33 children participated in a lowtech workshop on 29 June 2016. They created and customized paper ornaments, jumping-jack puppets and necklaces. In the period of July - November 2016, a series of three more low-tech FabLab workshops took place in which approximately 30 children participated. They experimented with some of the available machines to assemble and customize laser cut boxes, allowing them to familiarize with the FabLab's infrastructure and providing us with insights in their 'making' skills.

Third, informal group interviews were carried out (June December 2016). The researchers, youth workers and children discussed their experiences and expectations of the past and future workshops, including what they thought they had gained from them. We also carried out semi-structured interviews with three youth workers of LYWO (24 November and 15 December 2016). We included the youth workers in assessing children's users gains, as the children often talked to them about what they had gained from a workshop while the researchers were not present (e.g. on their way from the FabLab to LYWO's facilities).

The last phase consisted of four high-tech workshops (April November 2017). Approximately 50 children participated in these workshops, and experimented with electronics such as LittleBits (littlebits.cc): modular, magnetic building blocks. Afterwards, the workshops were, again, evaluated in terms of perceived user gains via semi-structured interviews with the youth workers and the children; the latter took on the form of a role play (for role playing in design processes, see e.g. [22]).

\subsection{Analysis}

Over two years of ethnographic fieldwork resulted in audio- and video recordings, sensitising packages, transcribed interviews, and logged field notes. The results reported in this paper were derived from analysing the qualitative data using a Grounded Theory strategy [23]. Various coding iterations resulted in the following categories, based on clustering of the codes: (1) developing self-esteem, (2) learning-by-doing, and (3) broadening the social environment as user gain.

\section{USER GAINS IN 'MAKING THINGS!'}

In the following part, we reflect on the results of the case study.

\subsection{Building self-esteem}


The results of 'Making Things!' - and specifically from workshops in which the children assembled and customized a pre-fabricated laser cut box - point to building self-esteem as a specific user gain. During the workshops, the children complained about the activity being difficult and actively sought the help of their peers, the youth workers and us. However, with some encouragement and (rather minor) assistance, most of the children were eventually able to assemble the boxes their selves (see: Fig. 1). As soon as the boxes were put together, the children expressed a sense of pride: "'Look what I made!", and the fact that they took their boxes home and worked further on them, that's fantastic?' (interview youth worker, 27 Oct. 2017). According to the youth workers, these experiences are essential for increasing children's self-esteem: "that's important, the fact that they learn that although this (...) doesn't seem feasible in the beginning, once they persevere, (...), they're able to do it. And then, over time, you'll start to notice that the children start to believe in themselves as well' (interview youth worker, 24 Nov. 2016). Through demonstrating their competence in assembling the boxes, but also in co-designing the workshops, the children developed a confidence in themselves, their (designer)skills and persistence. The youth workers noticed how, throughout the project, the children "are blossoming, in that sense" (interview youth worker, 27 Oct. 2017).

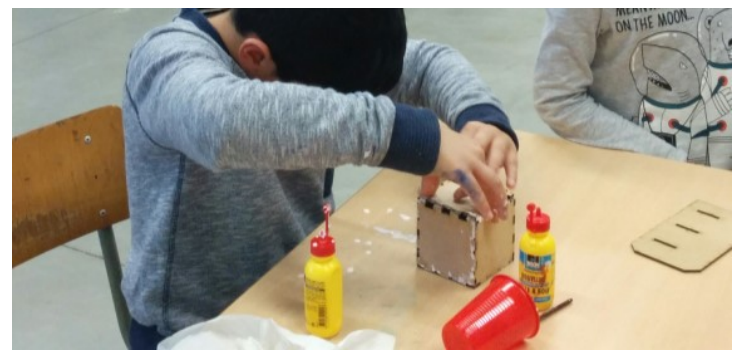

Figure 1: child-participant struggling to assemble the box.

These findings correspond to Hart's [24] idea that including a range of situations where children can demonstrate competence may increase their self-esteem. Children born in low-income households - such as the participants in 'Making Things!' - are more likely to suffer from low self-esteem and feel that they are "useless" or a "failure" [25, p. 30]. Low self-esteem also influences success at school, acceptance by their peers, and increases risk at depression [26]. In this sense, building self-esteem is particularly relevant for vulnerable children.

\subsection{Learning-by-doing}

'Learning-by-doing' is a central notion in constructionism: a learning theory that centralizes the construction of mental models by learners in order to understand the world around them. Papert (in: [27, p. 4]) claims: "we learn best of all when we use what we learn to make something we really want". The interviews with the children and youth workers showed that this was also relevant for the children participating in the project. During 'Making Things!', the children appeared to be very result-driven and enjoyed having something finished at the end of the workshops: "they are focussed on the result and not on creating something" (interview youth worker, 27 Oct. 2017). For instance, in one of the workshops the children made a cube to produce spherical soap bubbles. The cube needed to be almost perfectly square to result in a lasting bubble, which appeared to be very difficult; only some children succeeded. The children did not experience this as being pleasant: "I just wanted to have my square bubble. I got very frustrated because I had to try over and over again" (interview Sükran, girl, 11 y/o, 8 Aug. 2017). To steer the children somewhat away from working towards a finalised object, we explicitly stimulated experimentation and integrated a learning-by-doing approach to show that things do not always work out. For instance, we organised a workshop with Makey Makey (makeymakey.com/), without aiming to work towards an end-result. The children could use anything as a keyboard, but we also included non-conductive elements to confront them with a process of trial-and-error (see: Fig. 2).

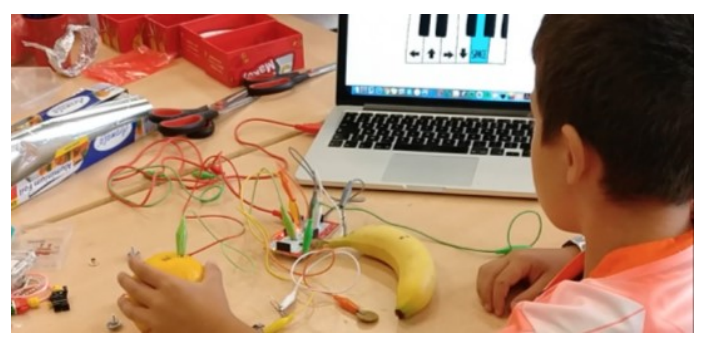

Figure 2: experimenting with the Makey Makey kit.

The youth workers noticed that through undergoing such a learning-by-doing approach the children learned to deal a bit better with experimenting: "it's about the steps and the process they undergo, (...) and that they know that, (...), there are things that I do not know. But I can get to know them step-by-step and that's okay" (interview youth worker, 27 Oct. 2017). This resulted in the children slowly moving away from working quickly towards a finalised object, as the PD project progressed. This became particularly evident during one of the workshops in which the children made a car with the LittleBits kits: "although the wheels didn't work, the boys really liked [creating cars with the LittleBits]" (interview youth worker, 24 Nov. 2016).

Previous studies (e.g. [28, 29]) have shown that vulnerable children do not always have opportunities to develop or apply a learning-by-doing approach in their direct environments. Horgan [30] pointed out that vulnerable children, attending schools in the more disadvantaged regions, are more likely to disengage from school. Moreover, they generally demonstrated a desire to have more 'learning-by-doing' opportunities.

\subsection{Broadening the children's horizons}

'Making Things!' showed that through participating the children broadened their horizons. They experienced participation as a way to escape their social housing flat and get acquainted with new technologies, other settings and people: "they want to break 
out, and come to us" (interview youth worker, 27 Oct. 2017). This relates to Griggs \& Walker's [29, p. 6] finding that vulnerable children may experience problems - e.g. with social contact when they live in an area "with few accessible, safe places to meet and inexpensive leisure facilities", as is the case in Genk-Zuid.

Another specific problem is the low parent participation, in comparison to other districts in Genk: "there is definitely a certain interest from the parents: "okay, what exactly is that, where did they go? And what are they doing there?" But it stops there" (interview youth worker, 24 Nov. 2016). These findings corroborate Ermisch \& Francesconi's [25] claim that for parents, their child's participation in PD projects may be difficult to understand, particularly when they themselves perceive little autonomy in their daily lives.

Moreover, the youth workers remarked that - similar to what Hussain \& Sanders [31] observed - the children are rarely encouraged to discuss or develop critical or creative skills at home. The youth workers made clear that through co-designing the workshops the children are provided with opportunities they would otherwise not have: "designing themselves, and giving them a bit more of a challenge in the assignments [is interesting]" (interview youth worker, 27 Oct. 2017).

\section{CONCLUSIONS AND DISCUSSION}

In this paper, we extend the debate on user gains in $\mathrm{PD}$ processes by exploring children's user gains. A central focus on what vulnerable children gain from involvement in PD - such as developing self-esteem, learning-by-doing, and broadening horizons - can lead to genuine forms of participation, fitting the values of the early-Scandinavian PD tradition $[5,7]$.

When designing for vulnerable children, user involvement is particularly important, as the cultural gap between designers and the target group is especially large [8]. Through 'Making Things!', we noticed that designing with vulnerable participants does pose some challenges. Time, willingness and the possibility to participate were often dependent on practical issues. For instance, the children were expected to contribute to the family household by looking after siblings (see also: [31]) and could tnot always participate in the PD activities. Another challenge entailed the language barrier; coming from mainly Turkish or Moroccan origin, some of the children did not speak Dutch very well. However, these children - although labelled as vulnerable are perfectly capable "of performing as other children or even adults who are not well-versed in the design process" [11, p. 12].

\subsection{Designing for vulnerability}

Focusing on the benefits that children gain through their participation is important for all children, but even more so for vulnerable ones. When designing for vulnerable participants, an approach to $\mathrm{PD}$ is required "that is sensitive to the risks of possible stigmatization" [13, p. 3231, 13]. Understanding the complexities of the participants and the society they live in, and showing cultural sensitivity is essential for enabling vulnerable children to have a positive design experience from which they can benefit $[9,32]$. Freire [33] describes the importance of a facilitator of empowerment, understanding the worldview of the participants. In 'Making Things!', we attempt to achieve this through developing relationships with the participants (i.e. children and youth workers) to build trust and more thoroughly understand their complexity. The long-term engagement with the participants as well as the great amount of PD activities facilitates this. Also, we continuously attempt to depart from what the child-participants can do, rather than what they cannot (cf. [34]). This resonates with PD involving children with ASD that focuses on the strengths of the participants as being beneficial for the design process, rather than the barriers ASD characteristics might pose (e.g. [10]). Furthermore, the approach of 'Making Things!' corresponds to LYWO's mission to empower children by seeing them as active individuals with their own strengths and possibilities, instead of victims [37]. In this sense, labelling people as being vulnerable is problematic, as the term may be perceived as stigmatizing or may lead to making people vulnerable $[13,14]$. Although we follow this argument and are aware of this sensitivity, we do recognize that the focus on vulnerability brings certain user gains to the surface that we otherwise might not have encountered. In future research, we foresee to reflect further upon this balance between labelling the participating children as 'vulnerable', yet exploring user gains specifically for vulnerable child-participants.

\subsection{Assessing user gains}

Assessing user gains - especially when done retrospectively - is not without its challenges and is almost always done by the researchers, not by the participants $[1,2,3]$. The assessment of participants' gains is not straightforward when children are involved. For instance, as children develop cognitively and emotionally at a quick rate, the application of certain methods for involving children in PD processes or evaluating them is dependent on several factors such as their verbal skills [35]. Therefore, we explored suitable methods for assessing user gains together with the child-participants in 'Making Things!'.

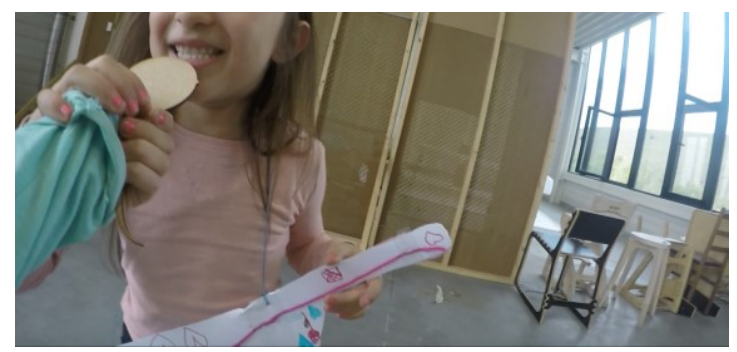

Figure 3: video still from an interview, as role play.

For instance, the semi-structured interviews with the children were carried out in the form of a role play. The children were asked to interview each other (based on verbal input from ourselves), while playing a reporter who was questioning an interviewee (see: Fig. 3). They were handed a Go-Pro camera and props (e.g. a laser cut microphone) to step into their roles. Additionally, we attempted to make our assessment as rich as 
possible by including interviews with the youth workers in different stages of the trajectory. In this way, we attempted to assess the children's user gains in a structured, meaningful way [3]. This provided us with an applicable starting point in our research, but we acknowledge that this is merely one way of assessing user gains. Therefore, in the continuation of the project, we intend to explore additional methods that might be relevant for assessing the benefits gained by the children.

\section{ACKNOWLEDGEMENTS}

'Making Things!' is funded by LUCA School of Arts' research platform. We thank the children and LYWO's youth workers for their participation.

\section{REFERENCES}

[1] Claus Bossen, Christian Dindler and Ole Sejer Iversen. 2010. User gains and PD aims: assessment from a participatory design project. Proceedings of the 11th biennial Participatory Design Conference, Sydney, Australia, 29 November 3 December 2010: Participation: the Challenge, (PDC '10), 141-150.

[2] Claus Bossen, Christian Dindler and Ole Sejer Iversen. 2012. Impediments to user gains: experiences from a critical participatory design project. Proceedings of the 12th biennial Participatory Design Conference, PDC 2012, Roskilde, Denmark, 12-16 August 2012: Embracing New Territories of Participation, Volume I, 31-40.

[3] Julia A. Garde and Mascha C. Van Der Voort. 2014. Participants' view on personal gains and PD process. Proceedings of the 13th biennial Participatory Design Conference, Windhoek, Namibia, 6-10 October 2014: Reflecting Connectedness, Volume II, 79-82.

[4] Wolmet Barendregt, Tilde M. Bekker, Peter Börjesson, Eva Eriksson and Olof Torgersson. 2016. Legitimate Participation in the Classroom Context: Adding Learning Goals to Participatory Design. Proceedings of the 15th International Conference on Interaction Design and Children, Manchester, United Kingdom, 21-24 June 2016, (IDC '16), 167-174.

[5] Pelle Ehn and Richard Badham. 2002. Participatory Design and the Collective Designer. Proceedings of the 7th biennial Participatory Design Conference, Malmö, Sweden, 23 - 25 June 2002: Inquiring into the Politics, Contexts and Practices of Collaborative Design Work, 1-10.

[6] Ole Sejer Iversen, Rachel Charlotte Smith and Christian Dindler. 2017. Child as Protagonist: Expanding the Role of Children in Participatory Design. Proceedings of the 2017 conference on Interaction design and children, Stanford, California, USA, 27-30 June 2017, 27-37.

[7] Netta Iivari, Marianne Kinnula and Leena Kuure. 2015. With best intentions: A Foucauldian examination on children's genuine participation in ICT design. Information Technology \& People, 28(2), 246-280.

[8] UNICEF. 2016. Ending Extreme Poverty: A Focus on Children. Sustainable Development Goals in Rich Countries.

[9] Sofia Hussain. 2010. Empowering marginalised children in developing countries through participatory design processes. CoDesign 6.2, 99-117

[10] Laura Benton, Hilary Johnson, Emma Ashwin, Mark Brosnan and Beate Grawemeyer. 2012. Developing IDEAS: supporting children with autism within a participatory design team. Proceedings of the SIGCHI Conference on Human Factors in Computing Systems, Austin, Texas, USA, 5-10 May 2012, 2599-2608.

[11] Seo Yun Yang. 2010. Participatory Design with Former Street Children: Benefits to Designers and Users. DEA Undergraduate Honors, Cornell University.

[12] Brenna McNally, Matthew Louis Mauriello, Mona Leigh Guha, and Allison Druin. 2017. Gains from Participatory Design Team Membership as Perceived by Child Alumni and their Parents. Proceedings of the 2017 CHI Conference on Human Factors in Computing Systems (CHI '17). ACM, New York, NY, USA, 5730-5741.

[13] John Vines, Roisin McNaney, Rachel Clarke, Stephen Lindsay, John McCarthy, Steve Howard, Mario Romero and Jayne Wallace. 2013. Designing for - and with - vulnerable people. In: CHI'13 Extended Abstracts on Human Factors in Computing Systems, 3231-3234.

[14] Alma Leora Culén and Anna Karpova. 2014. Designing with vulnerable children: A researchers perspective. Human-Computer Interfaces and Interactivity: Emergent Research and Applications: Emergent Research and Applications, 118.

[15] Sharon Lynn Chu, Francis Quek, Sourabh Bhangaonkar, Amy Boettcher Ging and Kumar Sridharamurthy. 2015. Making the Maker: A Means-to-an-Ends approach to nurturing the Maker mindset in elementary-aged children. International fournal of Child-Computer Interaction, 5, 11-19.
[16] Katrien Dreessen, Selina Schepers and Danny Leen. 2016. From Hacking Things to Making Things. Rethinking making by supporting non-expert users in a FabLab. IxD\&A fournal, 30, 47-64.

[17] Selina Schepers, Katrien Dreessen and Bieke Zaman. 2017. Rethinking children's roles in participatory design: The child as a process designer. International fournal of Child-Computer Interaction, 16, 47-54.

[18] Janet C. Read, Daniel Fitton, and Matthew Horton, 2014. Giving Ideas an Equal Change: Inclusion and Representation in Participatory Design with children. Proceedings of the IDC2014 (Aarhus, Denmark 2014), ACM, $105-114$.

[19] Allison Druin. 1999. Cooperative Inquiry: Developing New Technologies for Children with Children. Proceedings of CHi'99, Pittsburgh, PA, USA, May 15-20, 592-599.

[20] Kathleen Musante and Billie R. DeWalt. 2010. Participant observation: A guide for fieldworkers. Second Edition. Maryland, USA: Rowman Altamira.

[21] Maarten Van Mechelen, Bieke Zaman, Vero vanden Abeele and Ann Laenen. 2015. Co-design revisited: exploring problematic co-design dynamics in kids. Proceedings of the SIGCHI Conference on Human Factors in Computing Systems, Paris, France, 27 April - 2 May 2013, 1-6.

[22] Kristian T. Simsarian. 2003. Take it to the next stage: the roles of role playing in the design process. In: CHI'03 extended abstracts on Human factors in computing systems, 1012-1013.

[23] Barney Glaser and Anselm Strauss. 1967. Grounded theory: The discovery of grounded theory. Sociology The fournal Of The British Sociological Association, 12, 27-49.

[24] Roger Hart. 1992. Children's participation: From Tokenism to citizenship. Innocenti Essays, 4.

[25] John Ermisch and Marco Francesconi. 2001. Family matters: Impacts of family background on educational attainments. Economica, 2001, 68.270, 137-156.

[26] Arjan E. R. Bos, Peter Muris, Sandra Mulkens and Herman P. Schaalma. 2006 Changing self-esteem in children and adolescents: A roadmap for future interventions. Netherlands fournal of Psychology, 62.1, 26-33.

[27] Seymour Papert. 2005. The Eight Big ideas of the Constructionist Learning Laboratory, unpublished document quoted in Gary Stager, Papertian Constructionism and the Design of Productive Contexts for Learning. In Proceedings of Eurologo, 46.

[28] Jonathan Birdwell, Ralph Scott and Dale Koninckx. 2015. Learning by doing. London: Demos.

[29] Julia Griggs and Robert Walker. 2008. The costs of child poverty for individuals and society: a literature review. York: Joseph Rowntree Foundation.

[30] Goretti Horgan. 2007. The impact of poverty on young children's experience of school. York: Joseph Rowntree Foundation.

[31] Sofia Hussain and Elizabeth B.-N. Sanders. 2012. Fusion of horizons: Codesigning with Cambodian children who have prosthetic legs, using generative design tools, CoDesign, 8:1, 43-79

[32] Christopher R. Wilkinson and Antonella De Angeli. 2014. Applying user centred and participatory design approaches to commercial product development. Design Studies, 35.6, 614-631.

[33] Paulo Freire. 1970. Pedagogy of the Oppressed, trans. Myra Bergman Ramos, New York: Continuum, 65-80.

[34] John Vines et al. 2014. Special topic: Designing for and with vulnerable people. Interactions, 21.1, 44-46.

[35] Allison Druin. 2002. The role of children in the design of new technology. Behaviour and information technology, 21(1), 1-25. 